\title{
Corneal Lenticule Implantation in Keratoconus Disease with Relex Smile Surgery
}

\author{
Faruk Semiz*, Anita Syla Lokaj, Njomëza Hima and Olcay Semiz \\ Department of Ophthalmology, Eye Hospital, Prishtina, Kosova \\ *Corresponding Author: Faruk Semiz, Department of Ophthalmology, Eye \\ Hospital, Prishtina, Kosova.
}

Received: June 04, 2020

Published: June 24, 2020

(C) All rights are reserved by Faruk Semiz., et al.

\begin{abstract}
Purpose: The aim of our study is to investigate the feasibility and effect of fresh lenticule implantation as allogenic graft that will be taken from myopic patients to implant in patients with keratoconus disease using VisuMax Femtosecond laser-Smile module surgery with primary objective to increase central corneal thickness and secondary to improve visual acuity and reduces K-values.

Methods: All the patients were clinically diagnosed with progressive keratoconus. Twenty patients underwent SMILE surgery (first group), and 20 patients underwent lenticule implantation (lenticule group). Visual acuity, corneal topography, anterior segment optical coherence tomography, were analyzed.

Results: Central corneal thickness were improved at the same day of surgery and vision started to improved at first week postoperatively in the lenticule implant group. Corneal topography showed a statistically significant decrease in the anterior K1 and K2. All the grafts from both groups were clearly visible by anterior segment optical coherence tomography observation. The central corneal thickness was stable during the 6-month study period. No complications were observed during short term follow-up.

Conclusion: In conclusion, the present study may suggest that this procedure using fresh lenticule with stromal stem cells and live keratocytes is safely, reliably, and effectively increase corneal thickness and improves visual acuity with no adverse effects, which may provide new avenues in the treatment of corneal ectasia.

Keywords: Keratoconus; Small Incision; Fresh Lenticule; Stromal Implantation; Stromal Stem Cells; Smile Surgery
\end{abstract}

\section{Introduction}

Keratoconus is a proinflammatory corneal disease that is characterized by progressive corneal ectasia and steepening resulting from central corneal thinning [1]. It has an incidence of $0.05 \%$, with an age range of 9 to 28 years [2]. Keratoconus seems to be a multifactorial disease with unknown exact etiology. However, biomechanical instability is thought to be one of the main causes [3]. At present, the main operative corrections for keratoconus are corneal collagen cross-linking (CXL) therapy and corneal transplantation. Collagen cross-linking therapy increases the biomechanical stability of the cornea [4].

However, halting progression resulting from corneal collagen cross-linking may only be transient [6]. Penetrating keratoplasty (PKP) is usually the preferred treatment to improve visual acuity [7]. Nevertheless, the graft survival rate reduces with time postoperatively from $98 \%$ to $86 \%$ between 1 and 20 years postoperatively, respectively $[8,9]$. One of the main challenges to suturebased transplantation in developing countries is the occurrence of a broken suture or infected suture site, which can easily result in infectious keratitis, tissue rejection, or even endophthalmitis due to lack of access to care or proper ocular medications. In addition to an increased risk of infection, careful and thoughtful removal of sutures is an important factor for controlling postoperative astigmatism $[19,20]$.

Corneal intrastromal implantation was first described by Barraquer. This inlay model does not affect the integrity of the corneal epithelium or endothelium. However, clinical application of this model is limited because of its invasiveness during creation of the intrastromal pocket and poor inlay materials. In a previous study, it was shown that there was no implant rejection after autotransplantation or xenotransplantation using a small-incision femtosecond laser-assisted corneal intrastromal implantation procedure in all rhesus monkeys during a 26-month study period [10]. Also found that the modified concave inlay lamellae changed corneal refractive power. In studies by Liu., et al. and Liu., et al. allogeneic lenticules were used to change the refractive power in the animal 
models [11-13]. Pradhan., et al. and Ganesh., et al. also found that the meniscus allogeneic lenticule from small incision lenticule extraction (SMILE) could reshape the cornea with the necessary precision to correct hyperopia in the recipient [14]. However, the concave lenticule might have more usage in keratectatic diseases and the use of this inlay allograft corneal implantation model, assisted by the femtosecond laser, has not been explored in patients with progressive keratoconus [15].

In the present study, we did the SMILE surgery in myopic patients to remove the minus diopter and the fresh lenticule produced from myopic correction are thicker in the center and gradually become thinner toward the periphery with a shape of convex-concave positive meniscus lens was taken from these patients and at the same day (some minutes after this) we implant this allogenic corneal lamella in human patients with progressive keratoconus. This large case series study showed that the implantation of positive meniscus lenticule is safely, feasible and increase central corneal thickness.

\section{Patients and Methods}

This is a prospective study design. After a detailed explanation of the procedure, informed consent letter was obtained from all patients including donor and recipients in accordance to Declaration of Helsinki All patients were diagnosed with keratoconus based on results from slit-lamp microscopy, corneal topography, and anterior segment optical coherence tomography (AS-OCT). A total of 20 consecutive patients (20 eyes) were enrolled in the study.

Inclusion criteria were clinical evidence of progressive keratoconus stage II- III keratoconus based on the Amsler-Krumeich classification system (indications for penetrating keratoplasty).

\section{Stage II}

1. Myopia and astigmatism from 5.00 to 8.00 .

2. Mean central K reading < 53.00D.

3. Absence of scarring.

4. Minimum corneal thickness $>400$

\section{Stage III}

1. Induced myopia and/or astigmatism $>8 \mathrm{D},<10 \mathrm{D}$.

2. Corneal radii $>53 \mathrm{D}$.

3. No central scars.

4. Corneal thickness $200-400 \mu \mathrm{m}$.

\section{Exclusion criteria were}

1. Active anterior segment pathologic features.

2. Corneal thickness over $420 \mu \mathrm{m}$.

3. Previous corneal or anterior segment surgery.
Baseline clinical examination included evaluation of uncorrected visual acuity (UCVA), best spectacle- corrected distance visual acuity (CDVA), slit-lamp biomicroscopy, dilated fundus examination, corneal topography with the ATLLAS (Zeiss, Jena Germany). Anterior Segment Optical Coherence Tomography (AS-OCT (Zeiss, Meditec, Jena Germany) for the corneal thickness profile were performed on all eyes before surgery and at 1-day post op, 1 week, 1, 3 and 6 month postoperatively.

\section{Surgical technique}

All surgical procedures were performed by the same surgeon under topical anesthesia. The main aim of the treatment was to increase corneal thickness in patients with keratoconus and corneal thickness under $420 \mu \mathrm{m}$. A secondary aim was to increase visual acuity and to reduce $\mathrm{K}$ values. The procedure is different for each case, with different approaching according to corneal thickness, the lenticule was insert in the thinnest part of cornea with the main purpose to stabilize nasal and temporal cornea regarding to center of cone -pupillary region, which $\mathrm{k}$ values are decreased and visual acuity increases.

\section{Donor cornea preparations}

The donor and recipient patient was notified and scheduled for treatment at the same day. The donor patient received SMILE surgery using VisuMax femtosecond laser. The refractive power till $-4.00 \mathrm{D}$ with $70-80 \mu \mathrm{m}$ of maximum lenticule thickness. The optical zone (lenticule diameter) and cap diameter were 6.5 and 7.5 $\mathrm{mm}$ respectively. After dissection of both anterior and posterior planes, the lenticule was extracted through 120-degree superior $3.5 \mathrm{~mm}$-incision and marked with a sterile marker-(Viscot-Medster). The lenticule was put into BSS solution for ten minutes and after that was implanted into recipient eyes.

\section{Lenticule implantation technique in recipient patients}

Under topical anesthesia, the Visumax femtosecond laser flapcut procedures (Carl Zeiss Meditec AG) with an energy cut index of $30 \mathrm{~nJ}(150 \mathrm{Nj})$, spot and track spacing surface cuts of $4.5 \mu \mathrm{m}$, spot and track side cuts $2.0 \mu \mathrm{m}$ were used to create an intrastromal pocket into the patient's cornea to receive donor lenticule. The stromal pocket diameter was set to 7.6- to 8.0-mm diameter (1 mm larger than the optical zone of the donor lenticule) and cap thickness set to $130 \mathrm{~mm}$ from corneal surface and a 4-mm superior incision. Hinge position flap was set at 90 degree, hinge angle 50 degree and hinge width $4 \mathrm{~mm}$, side cut angle 90 . The pocket was dissected using a blunt spatula followed by washed with normal saline. The positive meniscus lenticule shaped lenticule with the anterior aspect facing upward was held with lenticule forceps and gently inserted into the pocket through the 4-mm superior incision. 
Incision position changes according to the position to the highest $\mathrm{K}$ values. Current orientation was marked with sterile skin marker. The lenticule was positioned around the marked center of cone and ironed out from the surface using a blunt spatula. (Figure 2). Once centration ending the incision was mooed with sterile sponge to remove residual fluid form the interface and no contact lens applied. Postoperatively, antibiotic eye drops (Vigamox; A) were prescribed 5 times a day, and steroid eye drops 5 times a day (Maxidex) were prescribed with a tapering dose for 1 months, along with lubricating drops.

\section{Statistical analysis}
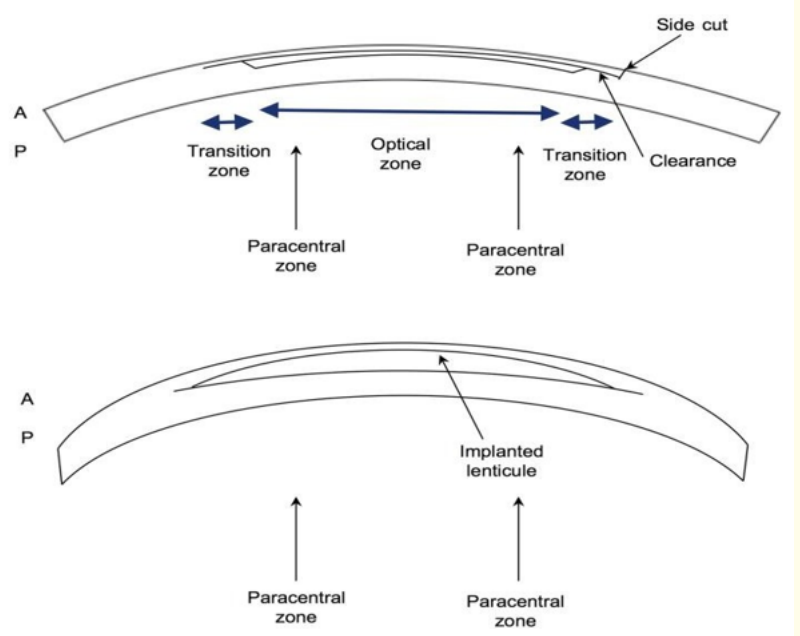

Figure 1: Diagrammatic representation of the steps involving recipient tissue preparation. A: SMILE lateral view of cornea showing optical (anterior cap) zone ( $6.5 \mathrm{~mm}$ diameter), the Clearance zone (1mm wide) and the 120 degrees lenticule side cut C, B. Lenticule shape: Showing the implanted lenticule. $\mathrm{A}=$ Anterior Cornea, $\mathrm{P}=$

\section{Posterior Cornea.}

All data are presented as mean +- SD. Visual acuity was measured using Snellen charts. For statistical analysis purposes, Snellen visual acuity was converted to the corresponding logarithm of the minimum angle of resolution value using standard conversion tables. Other outcome measures included, keratometry and corneal thickness.

\section{Results}

Slit-lamp microscopy

There were no intraoperative or postoperative complications at the end of each examination. All patients tolerated the procedure

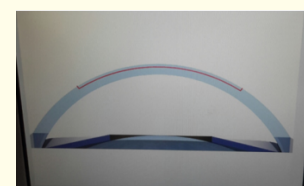

A
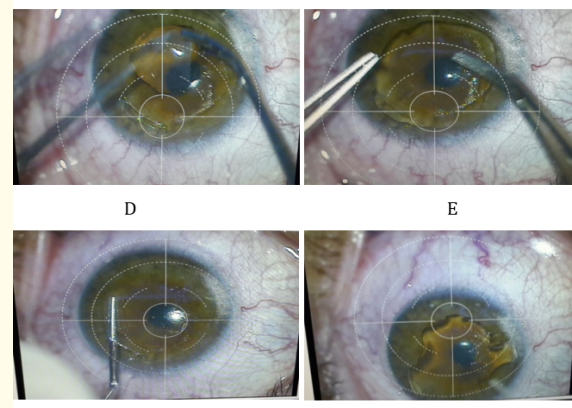

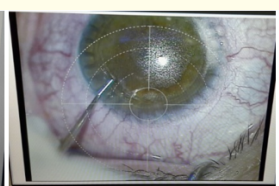

B

E

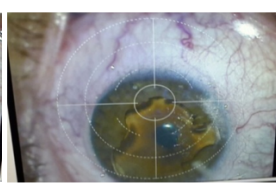

I

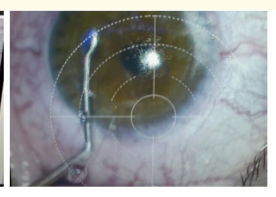

C

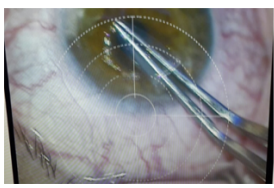

F

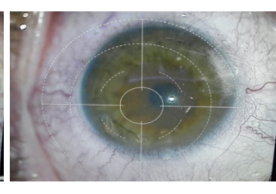

Figure 2: Schematic representation and phases of lenticule implantation in recipient cornea. (A)Using VisuMax free flap to create stromal pocket to implant fresh lenticule, (B) Stromal pocket in recipient cornea is dissected using blunt small incision spatula, (C) The stromal lenticule was grasped by forceps at this edge and inserted into recipient stromal pocket through small superior temporal incision, (D) The lenticule was distanced into the stromal pocket, (E) After the complete the lenticule distension then it was washout with saline.

well. Slit-lamp examination on day 1 showed mild corneal edema, which had subsequently cleared by day 7 . No reaction, infection, epithelial defects, punctate keratitis, deep lamellar keratitis, or signs of allogeneic rejection were observed in any of the treated eyes by the end of the follow-up period. After postoperative one month, the lenticule implantation were well integrated with surrounding tissue and the boundary of each lenticule were poorly defined but still visible 3 months postoperatively the boundary of lenticule were not visible and cornea was totally clear.

\section{Visual acuity and refraction}

The short term follow-up 6 months after surgery showed change in refraction and visual acuity. It was very interesting that in some patient they gained more minus diopter but reduced K-values and improved visual acuity. At 6 month postoperatively, UDVA showed an improvement in 15 cases and in 5 cases did not change but all cases showing improvement in CDVA. From 20 patients only one patient gain three lines in visual acuity, 5 eyes gained 2 lines and 14 cases gained one line. 


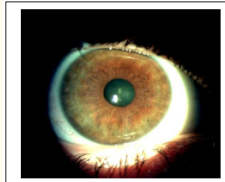

A

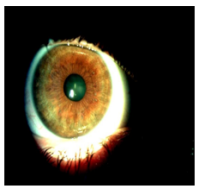

B

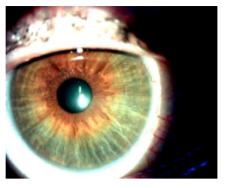

$\mathrm{C}$

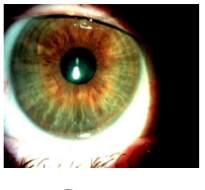

Figure 3: Slit-lamp microscopy photographs of corneas. (A) Preoperative and (B, C and D) postoperative features of cornea after stromal lenticule implantation. Cornea shows transparency from 1 week postoperatively.

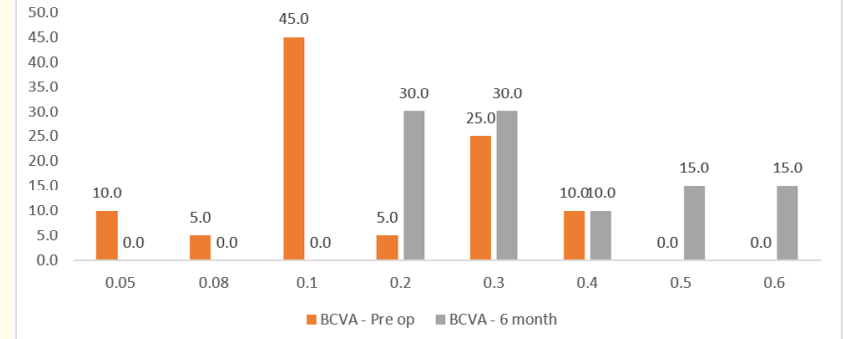

Figure 4: Corrected distance visual acuity (CDVA) at 6 months post-op compared with preoperative.

\begin{tabular}{|c|c|c|c|c|c|c|c|c|c|c|}
\hline \multirow[b]{2}{*}{ No. } & \multirow[b]{2}{*}{ Age/Gender } & \multirow[b]{2}{*}{ Eye } & \multicolumn{4}{|c|}{ Preoperative } & \multicolumn{4}{|c|}{ Follow-up 6 month } \\
\hline & & & Stage & Manifest Refraction & UDVA & CDVA & Manifest Refraction & UDVA & CDVA & $\begin{array}{l}\text { Change in } \\
\text { Lines of VA }\end{array}$ \\
\hline 1 & $20 / F$ & OD & II & $-2.25-6.25 \times 37$ & 0.05 & 0.3 & $-5.75-2.75 \times 27$ & 0.1 & 0.4 & 3 \\
\hline 2 & $25 / \mathrm{M}$ & OD & III & $-8.50-6.00 \times 10$ & 0.08 & 0.1 & $-6.50-2.75 \times 3$ & 0.1 & 0.2 & 1 \\
\hline 3 & $25 / \mathrm{M}$ & OD & III & $-8.50-6.00 \times 10$ & 0.08 & 0.1 & $-6.50-3.50 \times 65$ & 0.1 & 0.2 & 1 \\
\hline 4 & $23 / \mathrm{M}$ & OD & III & $-7.50-5.75 \times 7$ & 0.08 & 0.1 & $-4.50-4.25 \times 13$ & 0.4 & 0.6 & 2 \\
\hline 5 & $33 / \mathrm{M}$ & OS & II & $-6.00-4.25 \times 67$ & 0.1 & 0.2 & $-4.50-2.25 \times 161$ & 0.4 & 0.5 & 1 \\
\hline 6 & $33 / \mathrm{M}$ & OD & III & $-7.25-5.00 \times 39$ & 0.1 & 0.2 & $-5.00-3.55 \times 34$ & 0.2 & 0.4 & 2 \\
\hline 7 & $19 / \mathrm{F}$ & OS & III & $-6.50-5.50 \times 160$ & 0.1 & 0.2 & $-4.50-5.25 \times 158$ & 0.3 & 0.5 & 2 \\
\hline 8 & $38 / F$ & OD & II & $-4.50-5.25 \times 158$ & 0.1 & 0.1 & $-11.00-2.50 \times 90$ & 0.1 & 0.2 & 1 \\
\hline 9 & $38 / F$ & OS & III & $-8.50-2.50 \times 84$ & 0.1 & 0.4 & $-10.00-3.50 \times 108$ & 0.1 & 0.2 & 1 \\
\hline 10 & $27 / \mathrm{M}$ & OD & II & $-8.75-1.00 \times 72$ & 0.1 & 0.1 & $-11.00-2.50 \times 90$ & 0.1 & 0.2 & 1 \\
\hline 11 & $27 / \mathrm{M}$ & OS & III & $-8.50-2.50 \times 84$ & 0.1 & 0.3 & $-9.00-2.25 \times 160$ & 0.2 & 0.3 & 1 \\
\hline 12 & $22 / \mathrm{M}$ & OD & II & $-4.25-5.00 \times 78$ & 0.2 & 0.3 & $-4.00-3.75 \times 88$ & 0.3 & 0.4 & 1 \\
\hline 13 & $26 / \mathrm{F}$ & OS & III & $-8.00-5.75 \times 80$ & 0.05 & 0.1 & $-6.00-5.00 \times 65$ & 0.1 & 0.2 & 1 \\
\hline 14 & $31 / \mathrm{M}$ & OS & II & $-3.50-6.00 \times 75$ & 0.1 & 0.1 & $-4.00-4.50 \times 78$ & 0.1 & 0.2 & 1 \\
\hline 15 & $28 / \mathrm{M}$ & OD & III & $-7.25-6.25 \times 159$ & 0.05 & 0.1 & $-8.00-4.50 \times 65$ & 0.1 & 0.2 & 1 \\
\hline 16 & $26 / F$ & OD & II & $-5.00-4.50 \times 95$ & 0.1 & 0.1 & $-3.50-3.75 \times 95$ & 0.1 & 0.2 & 1 \\
\hline 17 & $23 / F$ & OD & III & $-6.50-5.50 \times 87$ & 0.08 & 0.1 & $-4.50-4.00 \times 90$ & 0.1 & 0.2 & 1 \\
\hline 18 & $28 / \mathrm{M}$ & OS & III & $-7.00-5.00 \times 106$ & 0.05 & 0.1 & $-5.25-4.75 \times 110$ & 0.1 & 0.2 & 1 \\
\hline 19 & $25 / \mathrm{M}$ & OS & III & $-10.00-6.00 \times 88$ & 0.04 & 0.08 & $-8.00-5.25 \times 90$ & 0.1 & 0.2 & 1 \\
\hline 20 & $30 / \mathrm{F}$ & OD & III & $-6.75-5.00 \times 100$ & 0.05 & 0.1 & $-7.00-4.00 \times 110$ & 0.1 & 0.2 & 1 \\
\hline
\end{tabular}

Table 1: Patient demographics and refractive data of patients treated with lenticule implantation.

Corneal topography

In all cases the corneal topography (ATLLAS, Zeiss, Meditec, Jena, Germany) showed changes in anterior keratometry values and flattening of the cone.

Pachymetry and anterior segment optical coherence tomography

Corneal lenticule implantation were visualized using AS-OCT and intrastromal lenticule implantation is visible in contrast to surrounding tissue. At 3 months, the implanted lenticule had a similar density, the boundary of the implanted lenticule were indistinguishable, with the little hyperreflection (Figure 6a-6c). At 6 months postoperatively, the cornea was clear and transparent and had the same density as surrounding tissue. Post-operative CCT pachymetry values increased in all cases as reported in table 3 and 4. The mean CCT values increased from $400.3+15.5$ to $478.9+9.1$ at 6 months follow-up (the follow-up is continued) $(\mathrm{P}<0.05)$. 

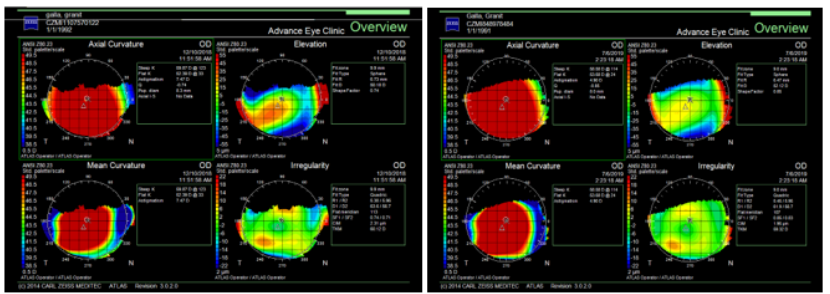

Pre op 1 day post op

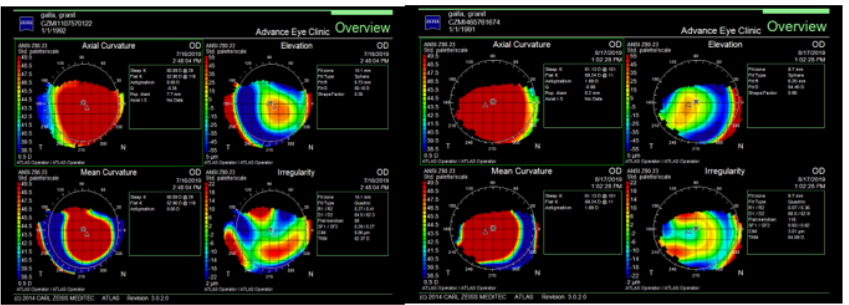

1 week post op 1 month post op

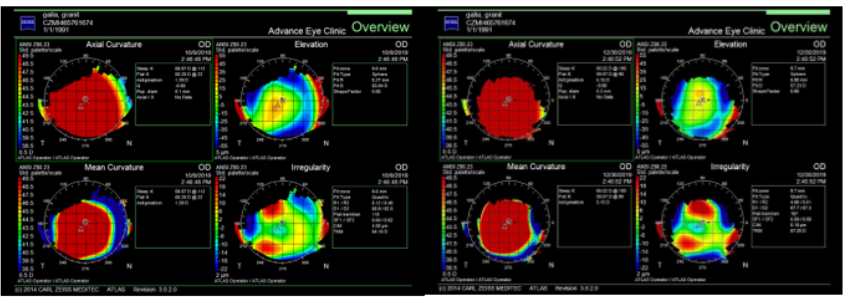

3 month post op 6 month post op

Figure 5: A series of corneal topography preoperative and postoperative visit 1 months, 3 months and 6 months postoperatively.
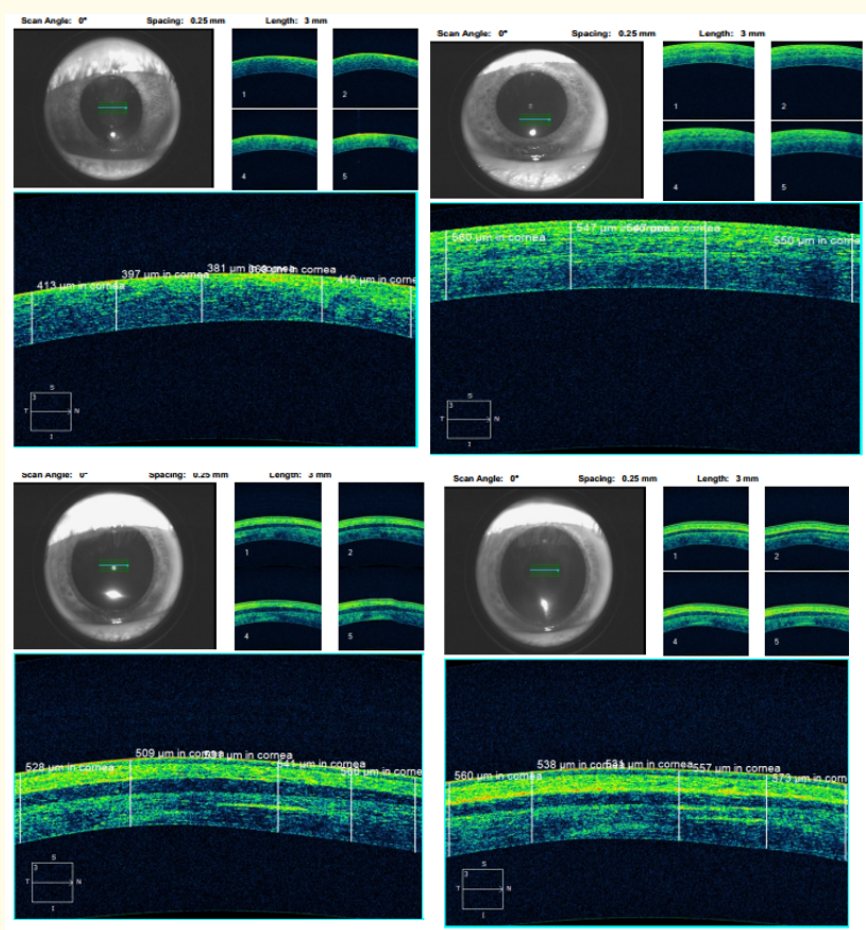
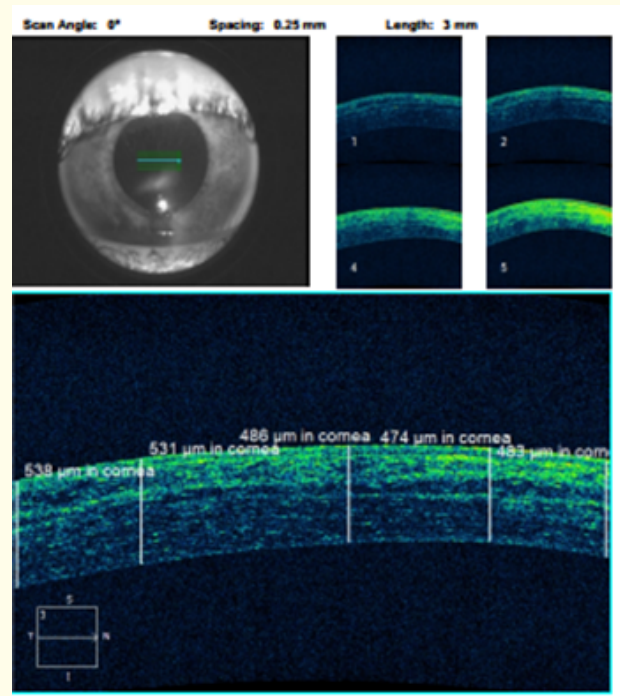

Figure 6: High resolution AS-OCT scan of the recipient cornea. (A) before the lenticule implantation and (B, C, D, E and F) showed 1 day post-op,1 week,1,3,6 month after surgery. Till 3 months lenticule interface show mild hyperreflection to the surrounding tissue. After 6 months the lenticule was well integrated with increase central corneal thickness.

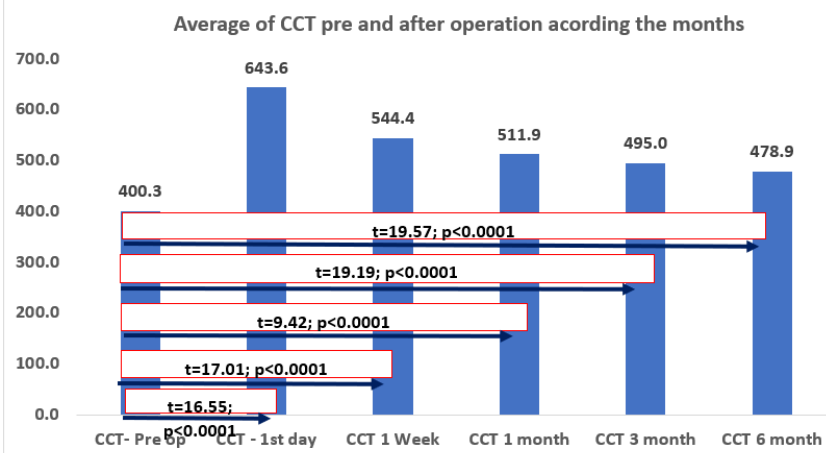

Figure 7: All patients were included in the study who measured pre- and postoperative CCT thickness, indicating that the mean preoperative CCT thickness was $400.3 \pm 15.5$ and compared with follow-up of patients after 1 day, 1 week, one month, At 3 months and after 6 months, we obtained a significant difference and the CCT thickness increased especially at month 1 to $511.9 \pm 24.8$ with a significant difference for $\mathrm{p}<0.00001$. Edema is present in the first week and this CCT thickness is expected. 


\begin{tabular}{|c|c|c|c|c|c|c|c|c|c|}
\hline $\mathrm{Nr}$ & $\mathrm{Nr}$ & Gender & Age & $\begin{array}{l}\text { K1-Pre } \\
\text { op }\end{array}$ & $\begin{array}{l}\text { K1-6 month } \\
\text { post op }\end{array}$ & $\begin{array}{l}\text { K2-pre } \\
\text { op }\end{array}$ & $\begin{array}{l}\text { K2-6 month } \\
\text { post op }\end{array}$ & $\begin{array}{l}\text { Changes K1, Pre } \\
\text { Op/k 1-6 Month }\end{array}$ & $\begin{array}{l}\text { Changes K2, Pre } \\
\text { Op/k 2-6 Month }\end{array}$ \\
\hline 1 & 1 & $\mathrm{~F}$ & 20 & 47.25 & 47.00 & 54.50 & 51.25 & 0.25 & 3.25 \\
\hline 1 & 2 & $\mathrm{M}$ & 25 & 49.25 & 49.00 & 55.53 & 52.25 & 0.25 & 3.28 \\
\hline 1 & 3 & M & 25 & 49.50 & 49.25 & 55.75 & 53.25 & 0.25 & 2.50 \\
\hline 1 & 4 & $\mathrm{M}$ & 23 & 48.25 & 47.25 & 53.50 & 52.25 & 1.00 & 1.25 \\
\hline 1 & 5 & M & 33 & 47.75 & 47.25 & 52.25 & 52.00 & 0.50 & 0.25 \\
\hline 1 & 6 & M & 33 & 48.75 & 48.50 & 53.75 & 51.25 & 0.25 & 2.50 \\
\hline 1 & 7 & $\mathrm{~F}$ & 19 & 47.50 & 47.25 & 53.25 & 52.50 & 0.25 & 0.75 \\
\hline 1 & 8 & $\mathrm{~F}$ & 38 & 48.50 & 48.50 & 53.75 & 51.50 & 0.00 & 2.25 \\
\hline 1 & 9 & $\mathrm{~F}$ & 38 & 49.25 & 49.50 & 52.50 & 52.00 & -0.25 & 0.50 \\
\hline 1 & 10 & M & 27 & 48.25 & 48.00 & 50.75 & 50.25 & 0.25 & 0.50 \\
\hline 1 & 11 & M & 27 & 48.50 & 48.25 & 51.75 & 51.00 & 0.25 & 0.75 \\
\hline 1 & 12 & $\mathrm{M}$ & 22 & 47.75 & 47.25 & 53.25 & 51.75 & 0.50 & 1.50 \\
\hline 1 & 13 & $\mathrm{~F}$ & 26 & 48.25 & 48.00 & 54.50 & 53.25 & 0.25 & 1.25 \\
\hline 1 & 14 & $\mathrm{M}$ & 31 & 48.00 & 48.00 & 53.75 & 51.50 & 0.00 & 2.25 \\
\hline 1 & 15 & $\mathrm{M}$ & 28 & 49.25 & 49.00 & 55.50 & 54.25 & 0.25 & 1.25 \\
\hline 1 & 16 & $\mathrm{~F}$ & 26 & 47.75 & 47.25 & 52.50 & 51.25 & 0.50 & 1.25 \\
\hline 1 & 17 & $\mathrm{~F}$ & 23 & 48.75 & 48.50 & 54.25 & 53.00 & 0.25 & 1.25 \\
\hline 1 & 18 & $\mathrm{M}$ & 28 & 49.25 & 49.00 & 54.75 & 54.00 & 0.25 & 0.75 \\
\hline 1 & 19 & $\mathrm{M}$ & 25 & 50.00 & 50.00 & 56.25 & 55.00 & 0.00 & 1.25 \\
\hline 1 & 20 & $\mathrm{~F}$ & 30 & 48.50 & 48.25 & 53.75 & 52.25 & 0.25 & 1.50 \\
\hline
\end{tabular}

Table 2: K-values pre-op and 6 month post-op.

\begin{tabular}{|c|c|c|}
\hline CT & Value & $\begin{array}{l}\text { t- test } \\
\text { P-value }\end{array}$ \\
\hline Average \pm SD of CCT- Pre op & $400.3 \pm 15.5$ & \\
\hline Average \pm SD of CCT $-1^{\text {st }}$ day & $643.6 \pm 57.4$ & $\begin{array}{c}\text { t-test }=16.55 \\
\mathrm{df}=38 \\
\mathrm{p}=0.00001\end{array}$ \\
\hline Average \pm SD of CCT 1 Week & $544.4 \pm 34.6$ & $\begin{array}{c}\text { t-test }=17.01 \\
\mathrm{df}=38 \\
\mathrm{p}=0.00001\end{array}$ \\
\hline $\begin{array}{l}\text { Average } \pm \text { SD of CCT } 1^{\text {st }} \\
\text { Month }\end{array}$ & $511.9 \pm 24.8$ & $\begin{array}{c}\text { t-test }=9.420 \\
\mathrm{df}=38 \\
\mathrm{p}=0.00001\end{array}$ \\
\hline Average \pm SD of CCT 3 Month & $495.0 \pm 15.8$ & $\begin{array}{c}\text { t-test }=19.19 \\
\mathrm{df}=38 \\
\mathrm{p}=0.00001\end{array}$ \\
\hline Average \pm SD of CCT 6 month & $478.9 \pm 9.1$ & $\begin{array}{c}\text { t-test }=19.57 \\
\mathrm{df}=38 \\
\mathrm{p}=0.00001\end{array}$ \\
\hline
\end{tabular}

Table 3

\begin{tabular}{|l|c|c|c|c|c|c|}
\hline Nr. & Gender & Age & $\begin{array}{c}\text { CCT- } \\
\text { Pre op }\end{array}$ & $\begin{array}{c}\text { CCT-6 } \\
\text { months } \\
\text { post op }\end{array}$ & $\begin{array}{c}\text { Lenticule } \\
\text { thickness }\end{array}$ & $\begin{array}{c}\text { Lenticule } \\
\text { diameter }\end{array}$ \\
\hline 1 & F & 20 & 402 & 470 & 68 & 6.5 \\
\hline 2 & M & 25 & 397 & 468 & 71 & 6.6 \\
\hline 3 & M & 25 & 394 & 480 & 86 & 6.6 \\
\hline 4 & M & 23 & 413 & 467 & 55 & 6.6 \\
\hline 5 & M & 33 & 413 & 470 & 57 & 6.6 \\
\hline 6 & M & 33 & 413 & 474 & 61 & 6.6 \\
\hline 7 & F & 19 & 381 & 480 & 99 & 6.6 \\
\hline 8 & F & 38 & 419 & 478 & 59 & 6.6 \\
\hline 9 & F & 38 & 420 & 470 & 50 & 6.6 \\
\hline 10 & M & 27 & 387 & 487 & 100 & 6.6 \\
\hline 11 & M & 27 & 381 & 497 & 116 & 6.6 \\
\hline 12 & M & 22 & 435 & 497 & 62 & 6.6 \\
\hline 13 & F & 26 & 402 & 492 & 90 & 6.6 \\
\hline 14 & M & 31 & 407 & 487 & 80 & 6.6 \\
\hline 15 & M & 28 & 387 & 478 & 91 & 6.6 \\
\hline 16 & F & 26 & 397 & 480 & 83 & 6.6 \\
\hline 17 & F & 23 & 385 & 474 & 89 & 6.6 \\
\hline 18 & M & 28 & 394 & 479 & 85 & 6.6 \\
\hline 19 & M & 25 & 390 & 472 & 82 & 6.6 \\
\hline 20 & F & 30 & 382 & 470 & 90 & 6.6 \\
\hline
\end{tabular}

Table 4 


\section{Discussion}

The cornea is a tough connective tissue presenting a formidable barrier between the eye and the outside world. More than $90 \%$ of the cornea is stroma, a highly organized, transparent connective tissue maintained by keratocytes, quiescent mesenchymal cells of neural crest origin. Unlike keratocytes, the corneal stromal stem cells (CSSCs) undergo extensive expansion in vitro without loss of the ability to adopt a keratocyte phenotype. Several lines of evidence suggest CSSCs to be of neural crest line-age and not from bone marrow. CSSCs are localized in the anterior peripheral (limbal) stroma near to stem cells of the corneal epithelium. CSSCs may function to support potency of the epithelial stem cells in their unique limbal niche. On the other hand, little information is available documenting a role for CSSCs in vivo in stromal wound healing or regeneration. In vitro CSSCs reproduce the highly organized connective tissue of the stroma, demonstrating a potential use of these cells in tissue bioengineering. Direct introduction of CSSCs into the corneal stroma generated transparent tissue in a mouse model of corneal opacity. Human CSSCs injected into mice corneas did not elicit immune rejection over an extended period of time [16].

Recent reports have described a keratocyte stem cell population in the anterior stroma (Du., et al. 2005; Funderburgh., et al. 2005). Ganesh., et al. reported 9 patients with hyperopia successfully receiving transplantation of an allogenic cryopreserved lenticule extracted from SMILE, but the stromal collagen fibers of cryopreserved lenticule were damaged because of freezing and throwing.

In our case series, central corneal thickness remained stable, and both CDVA and UDVA improved until 6 months after surgery (but more of these patients have reached ten to twelve months of follow-up). Our findings suggest that this surgical procedure can offer long-term stabilization and improve corneal thickness and visual outcomes in those with progressive keratoconus. Using fresh lenticule from donor myopic patients and implanted in recipient corneas with keratoconus through a small incision preserved normal structural anatomy of cornea. In this case series the patient recovered immediately, without complications, and both UDVA and CDVA significantly improved 1 week postoperatively. The target postoperative corneal thickness planned was approximately 470 $490 \mu \mathrm{m}$, a 75 - 85- $\mu \mathrm{m}$ increase from the preoperative pachymetry of $397-420 \mu \mathrm{m}$.

In our project we used only fresh lenticule that was taken from myopic patients at the same day of surgery, flap less method, stromal stem cell and live keratocytes with preserved anterior corneal lamella and plexus corneal nerves.
Because use of donor stromal lenticules is increasing and new methods for corneal refractive and disease treatment have been reported, it is important to consider a standard procedure for lenticule preparation. Although it is not as important in the current case where improving refraction was not the main outcome measure, like in our project, lenticule preparation is important if the main goal is refractive improvement. For example, Damgaard., et al. [20] reported standardized lenticule donor tissue preparation by using a 5-hour settling period between removal from the storage solution and excimer laser ablation [17]. But in our case series we did not storage longer than ten minutes after Smile surgery from donor patient, during this time we put only in BSS solution. Based on case that was done from Nepal, Pradhan and Reinstein they did only one case with lenticule from donor cornea from eye bank, corneal thickness was $425 \mu \mathrm{m}$ that differ from our case series [18].

One of the main challenges to suture-based transplantation in developing countries is the occurrence of a broken suture or infected suture site, which can easily result in infectious keratitis, tissue rejection, or even endophthalmitis due to lack of access to care or proper ocular medications. In addition to an increased risk of infection, careful and thoughtful removal of sutures is an important factor for controlling postoperative astigmatism [19,20].

Masterpasqou and his colleagues in their case series adding negative meniscus shape lenticule and it was taken from donor cornea from eye bank. Our opinion is that positive meniscus lenticule offer better opportunities because it is thick in the center and gradually become thinner in the periphery, this cause to increase corneal thickness and balance nasal and temporal side of corneal thickness. Also, lenticule thickness offer great advantages over intrastromal corneal ring because the ring is made from synthetic material and side effects like infections, extrusion, halos, glare are reported. In many case due to side effects many patients tend to have ICRS removed after few years. It could reshape the cornea but it will not increase the corneal thickness. Cross link procedure were no applied in our project because most of patients have corneal thickness under $400 \mu \mathrm{m}$ and lenticule implanted with stromal stem cell provide production of keratocytes and the latest give collagen fiber and extracellular matrix that are well organised into recipients corneal stroma.

This project report large number of cases in the human eyes with donor and recipient cornea that may prove useful in the armamentarium of the corneal surgeon for several corneal pathologies. Our predictive values are useful for all type of keratoconus but more useful for oval type of cone with diameter over $5 \mathrm{~mm}$ and localization paracentral-inferotemporal. 


\section{Conclusion}

In conclusion, the present study may suggest that this procedure is safely, reliably, and effectively increase corneal thickness and improves visual acuity with no adverse effects, which may provide new avenues in the treatment of corneal ectasia. Stem cell and live keratocytes are well organized based on cornea transparency and in anterior segment OCT.

This method is a good options for patients with keratoconus that need keratoplasty, because it preserve normal corneal anatomy, normal anterior lamella, this method is flapless method, the lenticule is fresh from donor patients, stromal stem cells with live keratocytes without needing to preserve it and healing process is faster.

This new treatment using only SMILE module for donor and recipient patients could be the new step to get the easy way for keratoconus disease because it also have very low cost comparison with penetrating keratoplasty and this method is less invasive, sutureless and more efficient than PKP.

\section{Bibliography}

1. Choi JA and Kim M-S. "Progression of Keratoconus by Longitudinal Assessment with Corneal Topography". Investigative Ophthalmology and Visual Science 53.2 (2012): 927-935.

2. Collier. "Is the corneal degradation in keratoconus caused by matrix-metalloproteinases?" Clinical and Experimental Ophthalmology (2019).

3. Daxer A and Fratzl P. "Collagen fibril orientation in the human corneal stroma and its implication in keratoconus". Investigative Ophthalmology and Visual Science 38.1 (1997): 121-129.

4. Wollensak G. "Crosslinking treatment of progressive keratoconus: new hope". Current Opinion in Ophthalmology 17.4 (2006): 356-360.

5. "Intracorneal rings for keratoconus and keratectasia". Journal of Cataract and Refractive Surgery (2019).

6. Brown S., et al. "Progression in Keratoconus and the Effect of Corneal Cross-Linking on Progression". Eye and Contact Lens: Science and Clinical Practice 40.6 (2014): 331-338.

7. Keane M., et al. "Deep anterior lamellar keratoplasty versus penetrating keratoplasty for treating keratoconus". Cochrane Database of Systematic Reviews 7 (2014): CD009700.
8. Kelly T-L., et al. "Repeat Penetrating Corneal Transplantation in Patients with Keratoconus". Ophthalmology 118.8 (2011): 1538-1542.

9. Zhang Y., et al. "Long-term comparison of full-bed deep anterior lamellar keratoplasty and penetrating keratoplasty in treating keratoconus". Journal of Zhejiang University Science B 14.5 (2013): 438-450.

10. Jin H., et al. "Comparison of femtosecond laser-assisted corneal intrastromal xenotransplantation and the allotransplantation in rhesus monkeys". BMC Ophthalmology (2017).

11. He M., et al. "Femtosecond Laser- Assisted Small Incision Endokeratophakia Using a Xenogeneic Lenticule in Rhesus Monkeys". Cornea 37.3 (2018): 354-361.

12. Liu R., et al. "Femtosecond Laser- Assisted Corneal Small Incision Allogenic Intrastromal Lenticule Implantation in Monkeys: A Pilot Study". Investigative Ophthalmology and Visual Science 56.6 (2015): 3715-3720.

13. Liu H., et al. "Femtosecond Laser Lenticule Transplantation in Rabbit Cornea: Experimental Study". Journal of Refractive Surgery 28.12 (2012): 907-911.

14. Reinstein DZ., et al. "Femtosecond Laser-Assisted Small Incision Sutureless Intrastromal Lamellar Keratoplasty (SILK) for Corneal Transplantation in Keratoconus". Journal of Refractive Surgery 35.10 (2019): 663-671.

15. Ganesh S., et al. "Cryopreservation of Extracted Corneal Lenticules after Small Incision Lenticule Extraction for Potential Use in Human Subjects". Cornea 33.12 (2014): 1355-1362.

16. Pinnamaneni N and Funderburgh JL. "Concise Review: Stem Cells in the Corneal Stroma”. Stem Cells 30.6 (2012): 10591063.

17. Damgaard IB., et al. "Reshaping and Customization of SMILEDerived Biological Lenticules for Intrastromal Implantation". Investigative Ophthalmology and Visual Science 59.6 (2018): 2555-2563.

18. Pradhan KR., et al. "Femtosecond Laser-Assisted Small Incision Sutureless Intrastromal Lamellar Keratoplasty (SILK) for Corneal Transplantation in Keratoconus". Journal of Refractive Surgery 35.10 (2019): 663-671. 
19. Hirst LW., et al. "Postoperative suture manipulation for control of corneal graft astigmatism". Australian and New Zealand Journal of Ophthalmology 26.3 (1998): 211-214.

20. Musch DC., et al. "The effect of removing running sutures on astigmatism after penetrating keratoplasty". Archives of Ophthalmology 106.4 (1988): 488-489.

\section{Assets from publication with us}

- Prompt Acknowledgement after receiving the article

- Thorough Double blinded peer review

- Rapid Publication

- Issue of Publication Certificate

- High visibility of your Published work

Website: www.actascientific.com/

Submit Article: www.actascientific.com/submission.php

Email us: editor@actascientific.com

Contact us: +919182824667 